\title{
THE
}

2013

\section{Antiproliferative Effect of pHLIP-Amanitin}

Anna Moshnikova

University of Rhode Island, a_moshnikova@uri.edu

Valentina Moshnikova

University of Rhode Island

Oleg A. Andreev

University of Rhode Island, andreev@uri.edu

Yana Reshetnyak

University of Rhode Island, reshetnyak@uri.edu

Follow this and additional works at: https://digitalcommons.uri.edu/phys_facpubs

This is a pre-publication author manuscript of the final, published article.

Terms of Use

All rights reserved under copyright.

\section{Citation/Publisher Attribution}

Moshnikova, A., Moshnikova, V., Andreev, O. A., \& Reshetnyak, Y. K. (2013). Antiproliferative Effect of pHLIP-Amanitin. Biochemistry, 52(7), 1171-1178. doi: 10.1021/bi301647y

Available at: https://doi.org/10.1021/bi301647y

This Article is brought to you for free and open access by the Physics at DigitalCommons@URI. It has been accepted for inclusion in Physics Faculty Publications by an authorized administrator of DigitalCommons@URI. For more information, please contact digitalcommons-group@uri.edu. 


\title{
Anti-proliferative effect of pHLIP-amanitin
}

\author{
Anna Moshnikova, Valentina Moshnikova, Oleg A. Andreev, and Yana K. Reshetnyak \\ Physics Department, University of Rhode Island, 2 Lippitt Rd., Kingston, RI, 02881
}

\section{Abstract}

Toxins could be effective anti-cancer drugs, if their selective delivery into cancer cells could be achieved. We have shown that the energy of membrane associated-folding of water-soluble membrane peptides of $\mathrm{pHLIP} \circledR(\mathrm{pH}$ Low Insertion Peptide) family could be used to move cellimpermeable cargoes across the lipid bilayer in cytoplasm of cancer cells. Here we present the results of a study of pHLIP-mediated cellular delivery of a polar cell-impermeable toxin, aamanitin, inhibitor of RNA polymerase II. We show that pHLIP can deliver a-amanitin into cells in a pH-dependent fashion and induce cell death within 48 hours. Translocation capability could be tuned by conjugating amanitin to the C-terminus of pHLIP via linkers of different hydrophobicity cleavable in cytoplasm. pHLIP-SPDP-amanitin, which exhibits 4-5 times higher anti-proliferative ability at $\mathrm{pH} 6$ compare to $\mathrm{pH} 7.4$, was selected as the best construct. The major mechanism of amanitin delivery is direct translocation (flip) across a membrane by pHLIP and cleavage of S-S bond in a cytoplasm. Anti-proliferative effect was monitored on four different human cancer cell lines. pHLIP-mediated cytoplasmic delivery of amanitin could open great opportunities to use the toxin as a potent $\mathrm{pH}$-selective anti-cancer agent, which predominantly targets highly-proliferative cancer cells with low extracellular $\mathrm{pH}$.

\section{INTRODUCTION}

One of the main goals of cancer treatment is to kill cancer cells without affecting cells in healthy tissues and organs. A number of toxic compounds have been tested; however, the side effects were significant. Therefore therapeutic use of these compounds is limited unless they would be delivered specifically to cancer cells. If the target of a polar therapeutic is cytoplasmic, the selective delivery of therapeutics to a tumor is not sufficient to improve treatment; it is necessary to move the drug molecule across cellular membrane and release it inside the cell. During the last decades various nanocarriers had been introduced for encapsulation of therapeutic payloads and delivery to tumors if tumor targeting molecules decorate nanocarriers $(1,2)$. The mechanism of cellular entry of nanocarriers is predominantly endocytotic, which leads to the trapping of therapeutic molecules in endosomes. $\mathrm{pH}$-sensitive functionalities could be incorporated into nanocarriers to promote disruption of endosomal membranes and facilitate payload release into the cytoplasm (3-7). We are developing a new approach for direct cytoplasmic delivery of polar cargo. Our concept is based on utilization of the energy of membrane-associated folding of family of pHLIPs ( $\mathrm{pH}$ Low Insertion Peptides) for the $\mathrm{pH}$-dependent translocation of cellimpermeable molecules across plasma membrane into the cytoplasm (8). We demonstrate targeting of acidic solid tumors by pHLIP peptides labeled with fluorescent, PET and SPECT imaging agents, delivery of gold nanoparticles and liposomes to acidic diseased tissue, and cytoplasmic delivery of various cell-impermeable molecules (9-16). Among functional cargo molecules tested for intracellular delivery by pHLIP were bi-cyclic hepta-

Author to whom correspondence should be addressed: Yana K. Reshetnyak, Physics Department, University of Rhode Island, 2 Lippitt Rd., Kingston, RI, 02881, USA, Phone: (401)-874-2060, Fax: (401) 874-2380, reshetnyak@ mail.uri.edu. 
peptides, mushroom phallotoxins $(8,17)$. The toxins were translocated into cultured cells in a pH-dependent manner, released into the cytoplasm by cleavage of S-S bond, and bound to intracellular target, F-actin. Phallatoxins delivered to cells by pHLIP induced stabilization of cell cytoskeleton, which led to cell death. We show that hydrophobicity of phallotoxin cargo could be tuned to enhance translocation (18). The objective of current study is an evaluation of pHLIP capability of translocating another mushroom toxin, bi-cyclic octa-peptide, $a$ amanitin. Despite the similarity in chemical structure between phallo and amanita toxins, they possess very different biological activity (19-21). Amanitin is an inhibitor of RNA polymerase II, inhibition of which blocks protein synthesis and induces cell death (22). This toxin could be considered as a potent anti-cancer drug if it could be specifically delivered to the cytoplasm of cancer cells. Here we demonstrate that pHLIP can deliver a-amanitin into cells in a pH-dependent fashion and induce cell death within 48 hours.

\section{MATERIALS AND METHODS}

\section{Materials and peptide preparation}

a-Amanitin, 4',6-diamidino-2-phenylindole (DAPI) and propidium iodine (PI) were purchased from Sigma-Aldrich, $N$-succinimidyl 3-(2-pyridyl-dithio)-propionate (SPDP) and sulfosuccinimidyl 6-[a-methyl-a-(2-pyridyldithio)toluamido]hexanoate (sulfo-Lc-SMPT), $\mathrm{N}$-[a-maleimidoacetoxy] succinimide ester (AMAS) were from Thermo Scientific, 6(fluorescein-5-carboxamido) hexanoic acid, succinimidyl ester (5-SFX) was from Invitrogen, and anexinV-FITC was from BD Biosciences. The pHLIP peptides with single Cys at the C- or N-terminus (pHLIP-Cys:

AEQNPIYWARYADWLFTTPLLLLDLALLVDADEGCT and Cys-pHLIP:

ACEQNPIYWARYADWLFTTPLLLLDLALLVDADEGT) were synthesized and purified by Dr. James I. Elliott at the W.M. Keck Foundation Biotechnology Resources Laboratory at Yale University (New Haven, CT).

\section{Conjugation of amanitin to pHLIP}

First, amanitin was conjugated with a cross-linker (cleavable SPDP, sulfo-Lc-SMPT, or non-cleavable, AMAS). Amanitin was incubated at room temperature for 4 hours with 10x excess of crosslinker in $50 \mathrm{mM}$ sodium phosphate buffer of $\mathrm{pH} 7.6$ containing $150 \mathrm{mM}$ sodium chloride followed by purification of the products by reverse phase HPLC. Next, Cys-pHLIP or pHLIP-Cys peptide was incubated with SPDP-amanitin or Lc-SMPTamanitin or AMAS-amanitin in $100 \mathrm{mM}$ sodium phosphate buffer $\mathrm{pH} 7.8$ (saturated with argon) containing $150 \mathrm{mM}$ sodium chloride at a ratio of $1: 1$ at room temperature for 1 hour. The final products were purified by reverse phase HPLC, lyophilized and characterized by SELDI-TOF mass-spectrometry. The concentration of constructs was determined by absorbance of amanitin at $310 \mathrm{~nm}$ using molar extinction coefficient of $13,000 \mathrm{M}^{-1} \mathrm{~cm}^{-1}$.

\section{Synthesis of amanitin-SFX}

Amanitin was incubated with 6-(fluorescein-5-carboxamido) hexanoic acid, succinimidyl ester (SFX) in $50 \mathrm{mM}$ sodium phosphate $150 \mathrm{mM}$ sodium chloride buffer $\mathrm{pH} 7.6$ at a ratio $1: 5$ at room temperature for 4 hours followed by purification of the product by reverse phase HPLC and characterized by SELDI-TOF mass-spectrometry.

\section{Measurements of water-octanol partition coefficient}

polarity of amanitin and amanitin conjugated to the SPDP or Lc-SMPT crosslinkers were determined by assessment of relative partitioning between aqueous and octanol liquid phases. Constructs dissolved in $\mathrm{MeOH}$ :water $1: 1$ were added to $0.5 \mathrm{ml}$ of $10 \mathrm{mM}$ phosphate buffer $\mathrm{pH} 7.4$ (saturated with argon), followed by the addition of argon saturated $n$-octanol 
$(0.5 \mathrm{ml})$ and sealed under argon. The solutions were mixed by rotation for 24 hours at room temperature and left for another $24-48$ hours for equilibration. After phase separation, absorption at $300 \mathrm{~nm}$ was recorded. molar extinction coefficients in $n$-octanol and phosphate buffer are assumed to be the same, and the ratio of the OD readings was used directly to calculate the partition coefficient, $P=\mathrm{OD}_{n \text {-octanol }} / \mathrm{OD}_{\text {water }}$, and $\log P$ values.

\section{Liposome preparations}

Liposomes were prepared by extrusion: POPC (1-palmitoyl-2-oleoyl-sn-glycero-3phosphocholine) was transferred to a round bottom flask, and a lipid layer was obtained by evaporating the choloroform in a rotary evaporator, followed by drying under high vacuum for 2 hours. The lipid layer was resuspended in $10 \mathrm{mM}$ phosphate buffer, $\mathrm{pH} 8$, and extruded 31 times through a $100 \mathrm{~nm}$ membrane to obtain large unilamellar vesicles.

\section{Steady-state fluorescence and circular dichroism measurements}

Intrinsic peptide fluorescence and circular dichroism (CD) spectra were measured on a PC1 ISS spectrofluorometer (ISS, Inc.) and a MOS-450 spectrometer (Biologic, Inc.), respectively. All measurements were performed at $25^{\circ} \mathrm{C}$. Samples of $2 \mu \mathrm{M}$ of pHLIP-SPDPAm and pHLIP-Lc-SMPT-Am incubated overnight in presence or absence of $2 \mathrm{mM}$ POPC in $\mathrm{pH} 8$ phosphate buffer were used for the measurements of $\mathrm{CD}$ and fluorescence signals of the states I and II. State I is the peptide in solution at $\mathrm{pH} 8$; state II is the peptide in the presence of POPC liposomes at $\mathrm{pH} 8$; state III reflects folding and insertion of the peptide into lipid bilayer of liposomes and formation of transmembrane helix, when $\mathrm{pH}$ is dropped from 8 to 3.6 by addition of an aliquot of $0.1 \mathrm{M} \mathrm{HCl}$. Peptide fluorescence spectra were recorded from $310 \mathrm{~nm}$ to $400 \mathrm{~nm}$ using excitation wavelength of $280 \mathrm{~nm}$. Peptide CD spectra were recorded from $190 \mathrm{~nm}$ to $260 \mathrm{~nm}$ in $0.5 \mathrm{~nm}$ increments using a sample cuvette with an optical path length of $0.5 \mathrm{~cm}$.

\section{pH-dependence}

pH-dependent partitioning of pHLIP-SPDP-Am into lipid bilayer was investigated by the shift of the position of the peptide intrinsic fluorescence spectral maximum for the pHLIP induced by a drop of $\mathrm{pH}$ from 8 to 3 by the addition of $\mathrm{HCl}$ in the presence of POPC liposomes. $2 \mu \mathrm{M}$ of the peptide was incubated overnight with $2 \mathrm{mM}$ of POPC liposomes, and $\mathrm{pH}$ was decreased by the addition of aliquots of $0.1 \mathrm{M} \mathrm{HCl}$. The resulting $\mathrm{pHs}$ were measured using a micro-electrode probe (Thermo Electron Corporation, Orion Ross Micro $\mathrm{pH}$ electrode). Fluorescence spectra were recorded at each $\mathrm{pH}$ value. The spectra were analyzed with decomposition algorithms using an on-line PFAST toolkit (Protein Fluorescence And Structural Toolkit: http://pfast.phys.uri.edu/ (23)) to obtain spectral maxima $\left(\lambda_{\max }\right)$. Finally, the positions of the fluorescence spectral maxima $\left(\lambda_{\max }\right)$ of the single component solutions were plotted versus $\mathrm{pH}$, and the Henderson-Hasselbalch equation was used to fit the data:

$$
\lambda_{\max }=\lambda_{2 \max }+\frac{\left(\lambda_{1 \max }-\lambda_{2 \max }\right)}{1+10^{(p H-p K a)}}
$$

where $\lambda_{1 \max }$ and $\lambda_{2 \max }$ are fluorescence maximum wavelengths at the beginning and end of the transition, respectively, and the $p K \mathrm{a}$ is the midpoint of the transition. It is assumed that there is a linear relation between the position of the maximum and the contribution of state II (or state III). However, due to the fact that quantum yields in states II and III are slightly different, there was a slight non-linearity. According to our previous estimation the apparent pK shifts no more than $0.05 \mathrm{pH}$ units toward lower $\mathrm{pHs}$ if quantum yields of state II and III are taken into account (24). Since this shift is less than the experimental error, we present 
the pKa values for transitions from the state II to III based on the analysis of the positions of spectral maxima and assuming that quantum yield is the same in states II and III.

\section{Cell lines}

Human cervix adenocarcinoma (HeLa) cells, human osteosarcoma (U2OS) cells, human breast ductal carcinoma M4A4 cells and human breast adenocarcinoma MDA-MB-231 cells were acquired from the American Type Culture Collection. Human cervix adenocarcinoma with stable expression of green fluorescent protein (GFP) HeLa-GFP cells was acquired from the Cell Biolabs Inc. Cells were authenticated, stored according to the supplier's instructions, and used within 3 months after frozen aliquot resuscitations. Cells were cultured in Dulbecco's Modified Eagle's Medium (DMEM) supplemented with 10\% fetal bovine serum (FBS), $10 \mu \mathrm{g} / \mathrm{mL}$ of ciprofloxacin in a humidified atmosphere of $5 \% \mathrm{CO} 2$ and $95 \%$ air at $37^{\circ} \mathrm{C}$. The $\mathrm{pH} 6.0$ medium was prepared by mixing $13.3 \mathrm{~g}$ of dry DMEM in $1 \mathrm{~L}$ of deionized water.

\section{Fluorescence Microscopy}

HeLa-GFP and HeLa cells were grown in 35-mm dishes with 14-mm glass-bottom windows coated with collagen. Cells were transferred to DMEM of pH 6.5 or 7.4 followed by incubation with 0.5-1 $\mu \mathrm{M}$ of pHLIP-S-S-amanitin at the same pHs for 2 hours. Control cells were treated with $1 \mu \mathrm{M}$ of staurosporine for 4 hours. After treatment construct was removed and cells were transferred to the standard growth medium. At various time points cells were stained with $5 \mu \mathrm{g} / \mathrm{ml}$ of DAPI or $2 \mu \mathrm{g} / \mathrm{ml}$ of PI for 20 min or Annexin V-FITC according to the manufacturer's instructions followed by intensive washing. Fluorescent and phasecontrast images of the cells were acquired with a Retiga CCD camera (Q-imaging) mounted onto the inverted Olympus IX71 microscope (Olympus America, Inc.). To monitor the changes in cell morphology in real time after treatment with pHLIP-S-S-amanitin, dishes with cells were placed in live cell imaging chamber (Tokai Hit).

\section{Proliferation Assay}

HeLa, U2OS, M4A4 or MDA-MB-231 cells were loaded in the wells of 96-well plates $(\sim 5,000$ cells per well) and incubated overnight. Growth medium was replaced with medium without FBS at $\mathrm{pH} 6.0$ or $\mathrm{pH} 7.4$ containing increasing amounts of constructs $(0.125,0.25$, 0.5 and $1 \mu \mathrm{M}$ and up to $10 \mu \mathrm{M}$ for amanitin and amanitin-SFX). In most cases treatment was performed in DMEM of pH 6.0 and 7.4, while in case of pHLIP-Lc-SMPT-amanitin treatment was performed in PBS pH 6.2 or 8.0. After 2 hours of treatment, the constructs were removed and replaced with standard growth medium containing 10\% FBS. Cell viability was assessed by colorimetric reagent (CellTiter $96 \mathrm{AQ}_{\text {ueous }}$ One Solution Assay, Promega), which was added for 1 hour to cells followed by measuring absorbance at 490 $\mathrm{nm}$. All samples were prepared in triplicate. Each experiment was repeated at least 3 times.

\section{ECIS Assay}

The kinetics of inhibition of proliferation of HeLa-GFP cells treated with pHLIP-SPDP-Am at $\mathrm{pH} 6.5$ were monitored by changes of capacitance measured at $\mathrm{AC}$ frequencies on an ECIS ${ }^{\circledR} 8 Z$ (electric cell-substrate impedance sensing) instrument (Applied Biophysics, Inc.). Cells ( 5,000 cells per well) were loaded in $8 \mathrm{~W} 10 \mathrm{E}+8$-well plate (Applied Biophysics Inc.) and incubated overnight. Each well had two sets of 20 circular $250 \mu \mathrm{m}$ diameter active gold electrodes. Growth medium was replaced with the medium without FBS of pH 6.0 or pH 7.4 containing $0.5 \mu \mathrm{M}$ of pHLIP-SPDP-amanitin or amanitin alone. The constructs were removed after 2 hours of treatment, and the cells were incubated in standard growth medium for 60 hours. Changes in capacitance were monitored for 50 hours after the treatment. The time of the treatment was set as zero. 


\section{RESULTS}

\section{Biophysical characterization of pHLIP-Amanitin interaction with membrane}

A bi-cyclic peptide, amanitin, containing a reactive $\mathrm{NH}_{2}$ group was conjugated with the $\mathrm{C}$ terminus of pHLIP via a cleavable S-S bond by two cross-linkers of different polarity: longchain hydrophobic Lc-SMPT and short-chain, more polar SPDP (Figure 1a). The three states of pHLIP-amanitin constructs were monitored by changes of peptide fluorescence excited at $280 \mathrm{~nm}$ (Figure 1b, d) and circular dichroism (Figure 1c, e) spectral signals. State I represents the construct in aqueous solution at $\mathrm{pH} 8$; addition of liposomes results in transition to state II, where the pHLIP peptide is in equilibrium between membrane-bound and free forms, and state III reflects insertion of the peptide into the lipid bilayer and formation of a transmembrane helix as the result of $\mathrm{pH}$ drop from 8 to 4 (25). The nonphysiological $\mathrm{pH}$ values of 8 and 4 were selected to ensure the completion of transition in this model experiment on liposomes. Both constructs show $\mathrm{pH}$-dependent interaction with the lipid bilayer of membrane. However, at $\mathrm{pH} 8$ in the presence of liposomes (state II, blue lines on Figure 1) the amount of membrane inserted form is higher for pHLIP-Lc-SMPTAm compared to pHLIP-SPDP-Am. This is reflected by a $3 \mathrm{~nm}$ shift of the position of maximum of fluorescence spectrum to short wavelengths ( $\lambda_{\max }$ of pHLIP-SPDS-Am and pHLIP-Lc-SMPT-Am in the state II is 347 and $344 \mathrm{~nm}$, respectively), an 11\% increase of fluorescence signal and a decrease of molar ellipticity at $220 \mathrm{~nm}(\Theta$ zof pHLIP-Lc-SMPTAm and pHLIP-Lc-SMPT-Am in the state II is $8.3 \times 10^{3}$ to $\left.6.8 \times 10^{3}, \mathrm{deg} \mathrm{cm}^{2} \mathrm{dmol}^{-1}\right)$. It could be explained by the difference in hydrophobicity of the amanitin cargo conjugated to the two different cross-linkers. Conjugation of the polar membrane-impermeable amanitin ( $\log P$ is about -2 , Figure $1 \mathrm{f}$ ) to the cross-linkers reduces the polarity of the constructs ( $\log P$ of amanitin-SPDP is about -0.2 ) and converts amanitin-Lc-SMPT cargo to slightly membrane permeable (positive value of $\log P=0.2$ ), which results in the higher affinity of pHLIP-Lc-SMPT-Am to the lipid bilayer of the membrane already at $\mathrm{pH} 8$. The cell experiments were mostly performed with pHLIP-SPDP-Am, which has an apparent $\mathrm{pK}$ of insertion into the membrane equal to 5.9, similar to the pHLIP peptide alone and to the pHLIP conjugated to phallatoxin and biotin cargoes $(18,24,26)$.

\section{Inhibition of cell proliferation}

Amanitin is a potent inhibitor of RNA polymerase II, which, once translocated into cells, induces their death. Amanitin is a polar molecule and cannot freely diffuse across the membrane, especially at low concentrations. The ability of pHLIP to move amanitin across the membrane and to inhibit cell proliferation in concentration- and $\mathrm{pH}$-dependent manners was evaluated on several cancer cell lines (Figure 2). Time of incubation of constructs with cells was varied, and the cytotoxic effect was evaluated using standard MTS assay at various time points. All data presented here were obtained at 2 hours of incubation of the constructs with cells, followed by the removal of the constructs and transfer of the cells to standard cell growth medium. Cell death was monitored at 48 hours after the treatment.

pH-Dependent inhibition of proliferation of HeLa cells treated with pHLIP-Lc-SMPT-Am was observed only when treatment was performed in PBS of pH 8 (Figure 2a), since at neutral $\mathrm{pH}$ cytotoxic effect was just slightly less compared to low $\mathrm{pH}$ treatment (data not shown). At the same time, the cytotoxic effect of pHLIP-SPDP-Am was significantly lower at $\mathrm{pH} 7.4$, while at $\mathrm{pH} 6.0$ concentration-dependent cell death was observed (Figure 2b). Cells treated with amanitin conjugated to the N-terminus of pHLIP (Am-SPDP-pHLIP) show slight toxicity at low $\mathrm{pH}$ at concentrations of $1 \mu \mathrm{M}$ (Figure $2 \mathrm{c}$ ), which might be associated with partial endocytotic uptake of the construct by the cells promoted by interaction of pHLIP with plasma membrane at low $\mathrm{pH}$ or the possibility of the insertion of some population of the peptide into cellular membrane translocating the $\mathrm{N}$-terminus across a 
bilayer. The cytotoxic effect after cells treatment with Am-SPDP-pHLIP was much lower compared to the effect after treatment with pHLIP-SPDP-Am. Another control experiment was performed with amanitin conjugated to the C-terminus of pHLIP via a non-cleavable cross-linker, AMAS, of similar polarity as SPDP (pHLIP-AMAS-Am). No cellular toxicity was observed at either $\mathrm{pHs}$ in a wide range of concentrations (Figure 2d), which confirms that amanitin needs to be released from the peptide to diffuse to the nucleus and find its target.

Treatment of various cancer cell lines including human osteosarcoma (U2OS), breast ductal carcinoma (M4A4) and breast adenocarcinoma (MDA-MB-231) with pHLIP-SPDP-Am led to the inhibition of cell proliferation in concentration- and $\mathrm{pH}$-dependent manners (Figure $2 \mathrm{e}-\mathrm{g}$ ). All cells were also treated with amanitin alone and no toxicity was observed (data not shown).

Besides the testing of the pHLIP-based constructs we evaluated the cytotoxic effect of amanitin conjugated with fluorescein-hexanoic acid (SFX), which contains protonatable carboxyl group and hexanoic acid for the enhancement of affinity of the construct to the membrane. Some $\mathrm{pH}$-dependent toxic effect was observed only at concentrations $(10 \mu \mathrm{M})$ 10 times higher than what was needed for the inhibition of cell proliferation by pHLIPSPDP-Am (Figure 2h).

\section{Kinetics of inhibition of cell proliferation}

The kinetics of inhibition of proliferation of HeLa-GFP cells treated with pHLIP-SPDP-Am at $\mathrm{pH} 6.5$ was monitored by the changes in capacitance measured at $\mathrm{AC}$ frequencies using ECIS (Figure 3a). Capacitance varies in a linear fashion with the fractional cell coverage of the bottom of a special chamber coated with thin film gold electrodes connected to the ECIS electronics (27). When cells are shrinking and dying after treatment with pHLIP-SPDP-Am the capacitance increased, reaching saturation at $40-50$ hours after the treatment. Changes in cell morphology were also observed on the optical microscope connected to the live-cell chamber (Figure $3 b-f$ ). In accordance to the capacitance measurements, the changes in cell morphology (rounding of the cells) were completed at $49 \mathrm{~h}$.

\section{Mechanism of cell death}

To evaluate the mechanism of cell death induced by pHLIP-SPDP-Am we monitored the appearance of phosphatidylserine on the outer surface of the plasma membrane and the DNA fragmentation, which are signs of early apoptosis. Non-treated HeLa cells and cells treated with pHLIP-SPDP-Am and staurosporine, which is known to induce apoptosis in HeLa cells $(28,29)$, were stained with cell-impermeable phosphatidylserine-binding protein, AnnexinV-FITC. The plasma membrane of cells at 4 hours after the treatment with staurosporine was stained with AnnexinV-FITC (Figure 4e), while the integrity of membrane was not compromised in most cases, since cell-impermeable DNA-staining dye, PI, was not able to label cellular nucleus (Figure 4f). Despite the fact that at 11 hours after the treatment with pHLIP-SPDP-Am some cells already underwent morphological changes (Figure 4a), we did not observe appearance of the phosphatidylserine on the outer leaflet of plasma membrane. Another sign of early apoptosis, DNA fragmentation, was evaluated on HeLa cells at various time points $(5,8,11,14$ and $17 \mathrm{~h})$ after treatment with pHLIP-SPDPAm by staining the cells with the membrane-impermeable DNA-binding dye, DAPI. The cells at selected time points after the treatment are shown on Figure $4 \mathrm{j}-\mathrm{o}$. With progression in time, the number of cells with changed morphology (Figure $4 \mathrm{j}, 1, \mathrm{n}$, shown by asterisk) was increasing, while the DNA fragmentation was occurring only in a small population (Figure $4 \mathrm{k}, \mathrm{m}, \mathrm{o}$, shown by arrows). We concluded that the major pathway of cell death after 
pHLIP-SPDP-Am treatment is necrotic; however we cannot exclude that apoptotic pathway could also be triggered in some subset of cells.

\section{DISCUSSION}

a-Amanitin belongs to the class of strong toxins and can induce cell death within 48 hours. However, it is too polar to cross cellular membrane by itself, except that of liver cells, which have a special transporting system for the uptake of small cyclic molecules like phallo- and amanita toxins (30). Amanitin could be considered as a potent anti-cancer drug if it can be delivered only to cancer cells and translocated across the membrane. Recently the antiproliferative effect of $a$-amanitin conjugated with anti-EpCAM antibody was tested on human cancer cell lines and assessed in vivo in immune-compromised mice bearing subcutaneous human pancreatic carcinoma xenograft tumors (31). The study suggested that anti-EpCAM antibody conjugates with a-amanitin have the potential to be highly effective therapeutic agents for pancreatic carcinomas and various EpCAM-expressing malignancies. Here we tested the capability of novel pHLIP-based drug delivery system to translocate aamanitin across the membrane into the cytoplasm. This system is based on a pH-dependent spontaneous insertion and folding of pHLIP peptide in the membrane. The molecular mechanism of pHLIPs action is a protonation of Asp/Glu residues in mildly acidic environment, which leads to the increase of hydrophobicity of the peptide and promotes peptide insertion and folding in the membrane. It is important to outline that in contrast to normal cells, cancer cells have a negative transmembrane $\mathrm{pH}$ gradient (extracellular $\mathrm{pHe}$ is lower than intracellular $\mathrm{pHi}$ ), which promotes accumulation of weak acids in cancer cells $(32,33)$. Thus, in cancer cells the equilibrium is shifted toward pHLIP inserted form, since Asp and Glu residues at the C-terminus of the peptide are de-protonated in cytoplasm in the environment of higher $\mathrm{pHi}$. The energy of membrane-associated folding (about $2 \mathrm{kcal} / \mathrm{mol}$ ) could be used to move polar cell-impermeable cargo molecules across lipid bilayer of membrane $(8,17,18,26)$. Our data indicate that the translocation capability could be tuned by conjugating amanitin to the C-terminus of pHLIP via more or less hydrophobic linkers. We found that pHLIP-SPDP-amanitin exhibits the most favorable properties demonstrating 4-5 times higher anti-proliferative ability at $\mathrm{pH} 6$ compared to $\mathrm{pH} 7.4$. The major mechanism of amanitin delivery is direct translocation across membrane by pHLIP and cleavage of the S-S bond in the cytoplasm. Amanitin conjugated to pHLIP via a noncleavable cross-linker was not able to induce cell death. Anti-proliferative effect was observed on four different human cancer cell lines. Most cells undergo necrosis, and cell death was observed at 40-50 hours after treatment. The cytotoxic effect was achieved as the result of cell treatment for 2 hours with the pHLIP-amanitin construct at concentrations of $0.25-1 \mu \mathrm{M}$. It could be very favorable for in vivo delivery, where the blood flow is significant and small therapeutic molecules have limited time for the accumulation in tumors. We already demonstrated that pHLIP targets acidic solid tumors of various origins with high accuracy and stains entire tumor mass to the degree that correlates with extracellular acidity $(10-12,14,34)$. Therefore, pHLIP might be effective in the delivery of phallo- and amanita-toxins to tumors and in their translocation across the membrane of cancer cells with low extracellular $\mathrm{pH}$ and reverse $\mathrm{pH}$ gradient. Amanitin will be most effective in killing highly-proliferative cancer cells, which actively synthesize proteins. Thus, selective death of cancer cells with minimal effect on normal cells might be achieved using pHLIP-mediated delivery of phallo- and amanita toxins.

\section{Acknowledgments}

Funding Source Statement: The work was supported by the NIH grants CA133890 to OAA and YKR. Work of V.M. was supported partially by the James Monroe summer research fellowship. Mass-spectrometry was done in RI-INBRE core facility funded by NCRR/NIH P20RR016457. 
We are grateful to Mr. D. Weerakkody (University of Rhode Island) and Dr. A. Karabadzhak (Yale) for the assistance in biophysical measurements.

\section{ABBREVIATIONS}

$\begin{array}{ll}\text { AC } & \text { alternating } \\ \text { Am } & \text { amanitin } \\ \text { AMAS } & \text { N-[a-maleimidoacetoxy] succinimide ester } \\ \text { CCD } & \text { charged coupled device } \\ \text { CD } & \text { circular dichroism } \\ \text { DAPI } & 4^{\prime} \text {,6-diamidino-2-phenylindole } \\ \text { DMEM } & \text { Dulbecco's Modified Eagle's medium } \\ \text { ECIS } & \text { electric cell-substrate impedance sensing } \\ \text { EPCAM } & \text { epithelial cell adhesion molecule } \\ \text { FBS } & \text { fetal bovine serum } \\ \text { FITC } & \text { fluorescein isothiocyanate } \\ \text { HPLC } & \text { high liquid pressure chromatography } \\ \text { OD } & \text { optical density } \\ \text { PET } & \text { positron emission tomography } \\ \text { PFAST } & \text { protein fluorescence and structural database } \\ \text { pHLIP } & \text { pH Low Insertion Peptide } \\ \text { PI } & \text { propidium iodide } \\ \text { POPC } & \text { 1-palmitoyl-2-oleoyl-sn-glycero-3-phosphocholine } \\ \text { SELDI-TOF } & \text { surface enhanced laser desorption ionization time-of-flight } \\ \text { SFX } & \text { 6-(fluorescein-5-carboxamido) hexanoic acid, succinimidyl ester } \\ \text { SPDP } & N \text {-succinimidyl 3-(2-pyridyl-dithio)-propionate } \\ \text { SPECT } & \text { single photon emission tomography } \\ \text { sulfo-Lc-SMPT } & \text { succinimidyl 6-[a-methyl-a-(2-pyridyldithio)toluamido]hexanoate }\end{array}$

\section{References}

1. Torchilin VP. Passive and active drug targeting: drug delivery to tumors as an example. Handb Exp Pharmacol. 2010:3-53. [PubMed: 20217525]

2. Cheng Z, Al Zaki A, Hui JZ, Muzykantov VR, Tsourkas A. Multifunctional nanoparticles: cost versus benefit of adding targeting and imaging capabilities. Science. 2012; 338:903-910. [PubMed: 23161990]

3. Boomer JA, Qualls MM, Inerowicz HD, Haynes RH, Patri VS, Kim JM, Thompson DH. Cytoplasmic delivery of liposomal contents mediated by an acid-labile cholesterol-vinyl ether-PEG conjugate. Bioconjug Chem. 2009; 20:47-59. [PubMed: 19072698]

4. Fattal E, Couvreur P, Dubernet C. "Smart" delivery of antisense oligonucleotides by anionic pHsensitive liposomes. Adv Drug Deliv Rev. 2004; 56:931-946. [PubMed: 15066753]

5. Guo X, Szoka FC Jr. Steric stabilization of fusogenic liposomes by a low-pH sensitive PEG--diortho ester--lipid conjugate. Bioconjug Chem. 2001; 12:291-300. [PubMed: 11312691] 
6. Simoes S, Moreira JN, Fonseca C, Duzgunes N, de Lima MC. On the formulation of pH-sensitive liposomes with long circulation times. Adv Drug Deliv Rev. 2004; 56:947-965. [PubMed: 15066754]

7. Turk MJ, Reddy JA, Chmielewski JA, Low PS. Characterization of a novel pH-sensitive peptide that enhances drug release from folate-targeted liposomes at endosomal pHs. Biochim Biophys Acta. 2002; 1559:56-68. [PubMed: 11825588]

8. Reshetnyak YK, Andreev OA, Lehnert U, Engelman DM. Translocation of molecules into cells by pH-dependent insertion of a transmembrane helix. Proc Natl Acad Sci U S A. 2006; 103:64606465. [PubMed: 16608910]

9. Andreev OA, Dupuy AD, Segala M, Sandugu S, Serra DA, Chichester CO, Engelman DM, Reshetnyak YK. Mechanism and uses of a membrane peptide that targets tumors and other acidic tissues in vivo. Proc Natl Acad Sci U S A. 2007; 104:7893-7898. [PubMed: 17483464]

10. Daumar P, Wanger-Baumann CA, Pillarsetty N, Fabrizio L, Carlin SD, Andreev OA, Reshetnyak YK, Lewis JS. Efficient (18)F-Labeling of Large 37-Amino-Acid pHLIP Peptide Analogues and Their Biological Evaluation. Bioconjug Chem. 2012; 23:1557-1566. [PubMed: 22784215]

11. Morrison SMS, Iveson P, Arbo BE, Andreev OA, Reshetnyak YK, Engelman DM, Johannesen E. In vivo pH imaging with (99m)Tc-pHLIP. Mol Imaging Biol. 2012; 14:725-734. [PubMed: 22371188]

12. Yao YKL, Zheng S, Kuznetsov S, Engelman DM, Andreev OA. Measuring tumor aggressiveness and targeting metastatic lesions with fluorescent pHLIP. Mol Imaging Biol. 2011; 13:1146-1156. [PubMed: 21181501]

13. Davies A, Lewis DJ, Watson SP, Thomas SG, Pikramenou Z. pH-controlled delivery of luminescent europium coated nanoparticles into platelets. Proc Natl Acad Sci U S A. 2012; 109:1862-1867. [PubMed: 22308346]

14. Vavere AL, Biddlecombe GB, Spees WM, Garbow JR, Wijesinghe D, Andreev OA, Engelman DM, Reshetnyak YK, Lewis JS. A novel technology for the imaging of acidic prostate tumors by positron emission tomography. Cancer Res. 2009; 69:4510-4516. [PubMed: 19417132]

15. Sosunov EA, Anyukhovsky EP, Sosunov AA, Moshnikova A, Wijesinghe D, Engelman DM, Reshetnyak YK, Andreev OA. pH (low) insertion peptide (pHLIP) targets ischemic myocardium. Proc Natl Acad Sci U S A. 2013; 110:82-86. [PubMed: 23248283]

16. Yao L, Danniels J, Moshnikova A, Kuznetsov S, Ahmed A, Engelman DM, Reshetnyak YK, Andreev OA. pHLIP peptide targets nanogold particles to tumors. Proc Natl Acad Sci U S A. 2012

17. An M, Wijesinghe D, Andreev OA, Reshetnyak YK, Engelman DM. pH-(low)-insertion-peptide (pHLIP) translocation of membrane impermeable phalloidin toxin inhibits cancer cell proliferation. Proc Natl Acad Sci U S A. 2010; 107:20246-20250. [PubMed: 21048084]

18. Wijesinghe D, Engelman DM, Andreev OA, Reshetnyak YK. Tuning a polar molecule for selective cytoplasmic delivery by a pH (Low) insertion peptide. Biochemistry. 2011; 50:1021510222. [PubMed: 22029270]

19. Wieland T, Faulstich H. Amatoxins, phallotoxins, phallolysin, and antamanide: the biologically active components of poisonous Amanita mushrooms. CRC Crit Rev Biochem. 1978; 5:185-260. [PubMed: 363352]

20. Vetter J. Toxins of Amanita phalloides. Toxicon. 1998; 36:13-24. [PubMed: 9604278]

21. Walton JD, Hallen-Adams HE, Luo H. Ribosomal biosynthesis of the cyclic peptide toxins of Amanita mushrooms. Biopolymers. 2010; 94:659-664. [PubMed: 20564017]

22. Stirpe F, Fiume L. Effect of alpha-amanitin on ribonucleic acid synthesis and on ribonucleic acid polymerase in mouse liver. Biochem J. 1967; 103:67P-68P.

23. Shen C, Menon R, Das D, Bansal N, Nahar N, Guduru N, Jaegle S, Peckham J, Reshetnyak YK. The protein fluorescence and structural toolkit: Database and programs for the analysis of protein fluorescence and structural data. Proteins. 2008; 71:1744-1754. [PubMed: 18175321]

24. Karabadzhak AG, Weerakkody D, Wijesinghe D, Thakur MS, Engelman DM, Andreev OA, Markin VS, Reshetnyak YK. Modulation of the pHLIP Transmembrane Helix Insertion Pathway. Biophys J. 2012; 102:1846-1855. [PubMed: 22768940] 
25. Reshetnyak YK, Segala M, Andreev OA, Engelman DM. A monomeric membrane peptide that lives in three worlds: in solution, attached to, and inserted across lipid bilayers. Biophys J. 2007; 93:2363-2372. [PubMed: 17557792]

26. Reshetnyak YK, Andreev OA, Segala M, Markin VS, Engelman DM. Energetics of peptide (pHLIP) binding to and folding across a lipid bilayer membrane. Proc Natl Acad Sci U S A. 2008; 105:15340-15345. [PubMed: 18829441]

27. Wegener J, Keese CR, Giaever I. Electric cell-substrate impedance sensing (ECIS) as a noninvasive means to monitor the kinetics of cell spreading to artificial surfaces. Exp Cell Res. 2000; 259:158-166. [PubMed: 10942588]

28. Tafani M, Minchenko DA, Serroni A, Farber JL. Induction of the mitochondrial permeability transition mediates the killing of HeLa cells by staurosporine. Cancer Res. 2001; 61:2459-2466. [PubMed: 11289115]

29. Nicolier M, Decrion-Barthod AZ, Launay S, Pretet JL, Mougin C. Spatiotemporal activation of caspase-dependent and -independent pathways in staurosporine-induced apoptosis of p53wt and p53mt human cervical carcinoma cells. Biol Cell. 2009; 101:455-467. [PubMed: 19216720]

30. Munter K, Mayer D, Faulstich H. Characterization of a transporting system in rat hepatocytes. Studies with competitive and non-competitive inhibitors of phalloidin transport. Biochim Biophys Acta. 1986; 860:91-98. [PubMed: 2873838]

31. Moldenhauer G, Salnikov AV, Luttgau S, Herr I, Anderl J, Faulstich H. Therapeutic potential of amanitin-conjugated anti-epithelial cell adhesion molecule monoclonal antibody against pancreatic carcinoma. J Natl Cancer Inst. 2012; 104:622-634. [PubMed: 22457476]

32. Kozin SV, Shkarin P, Gerweck LE. The cell transmembrane $\mathrm{pH}$ gradient in tumors enhances cytotoxicity of specific weak acid chemotherapeutics. Cancer Res. 2001; 61:4740-4743. [PubMed: 11406545]

33. Raghunand N, Altbach MI, van Sluis R, Baggett B, Taylor CW, Bhujwalla ZM, Gillies RJ. Plasmalemmal $\mathrm{pH}$-gradients in drug-sensitive and drug-resistant MCF-7 human breast carcinoma xenografts measured by 31P magnetic resonance spectroscopy. Biochem Pharmacol. 1999; 57:309-312. [PubMed: 9890558]

34. Segala J, Engelman DM, Reshetnyak YK, Andreev OA. Accurate Analysis of Tumor Margins Using a Fluorescent $\mathrm{pH}$ Low Insertion Peptide (pHLIP). International Journal of Molecular Sciences. 2009; 10:3478-3487. [PubMed: 20111691] 

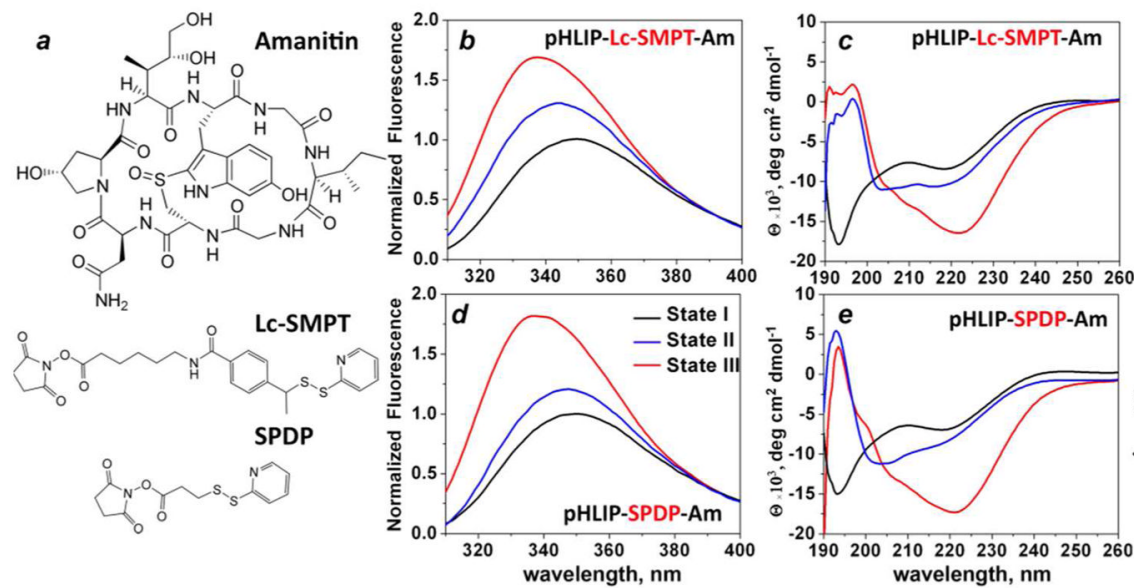

$\boldsymbol{f}$

Amanitin, $\log P=-2.0$

LC-SMPT-Amanitin, $\log P=0.2$

SPDP-Amanitin, $\log P=-0.2$

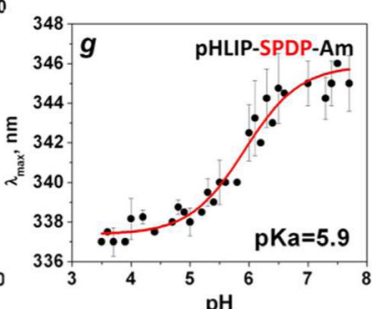

Figure 1. Interaction of pHLIP-amanitin with lipid bilayer of liposomes

a) Chemical structure of amanitin, long-chain (Lc-SMPT) and short-chain (SPDP) crosslinkers. Fluorescence $(\boldsymbol{b}, \boldsymbol{d})$ and $\mathrm{CD}(\boldsymbol{c}, \boldsymbol{e})$ spectra representing three states of pHLIPamanitin conjugated via long-chain, SMPT, $(\boldsymbol{b}, \boldsymbol{c})$ and short-chain, SPDP, $(\boldsymbol{d}, \boldsymbol{e})$ cross-linkers are shown. State I corresponds to the construct in aqueous solution at $\mathrm{pH} 8$, addition of liposomes results in formation of state II, and state III represents peptide inserted into lipid bilayer at $\mathrm{pH} 4 . f) \log P$ values of amanitin and its conjugates with long- and short-chain cross-linkers are shown (where $P$ is the octanol-water partition coefficient). $d$ ) The $\mathrm{pH}$ dependence of pHLIP-SPDP-Am transition from the state II to the state III is shown. 

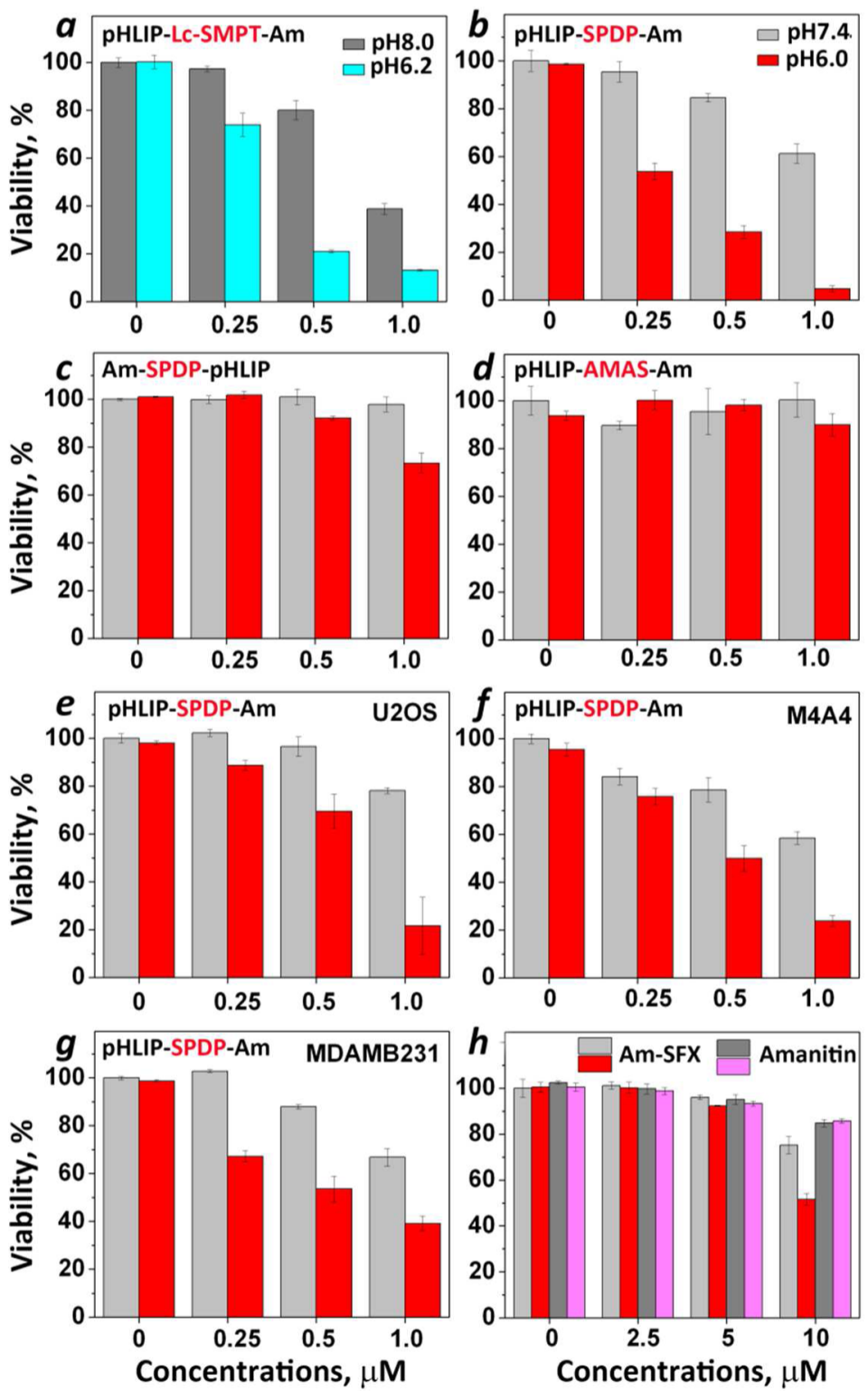

Figure 2. Inhibition of cell proliferation

Human cervix adenocarcinoma, HeLa-GFP $(\boldsymbol{a}-\boldsymbol{d}, \boldsymbol{h})$ human osteosarcoma, U2OS $(\boldsymbol{e})$, human breast ductal carcinoma M4A4 $(f)$ and human breast adenocarcinoma MDA-MB-231 (g) were treated with the following constructs: pHLIP-Lc-SMPT-Am $(\boldsymbol{a})$, pHLIP-SPDP-Am $(\boldsymbol{b}$, $\boldsymbol{e}-\boldsymbol{g})$, Am-SPDP-pHLIP $(\boldsymbol{c})$, pHLIP-AMAS-AM $(\boldsymbol{d})$, amanitin-SFX and amanitin alone $(\boldsymbol{h})$ for 2 hours in DMEM of normal/high pH (light and dark gray columns) or low $\mathrm{pH}$ (pH $6.2-$ blue column and $\mathrm{pH} 6.0$ - red and magenta columns) followed by the removal of the constructs and the transfer of cells to standard cell growth medium, MTS assay was performed at 48 hours after the treatment. Amanitin and pHLIP alone have no effect on proliferation of all investigated cell lines at both $\mathrm{pHs}$ (data not shown). 

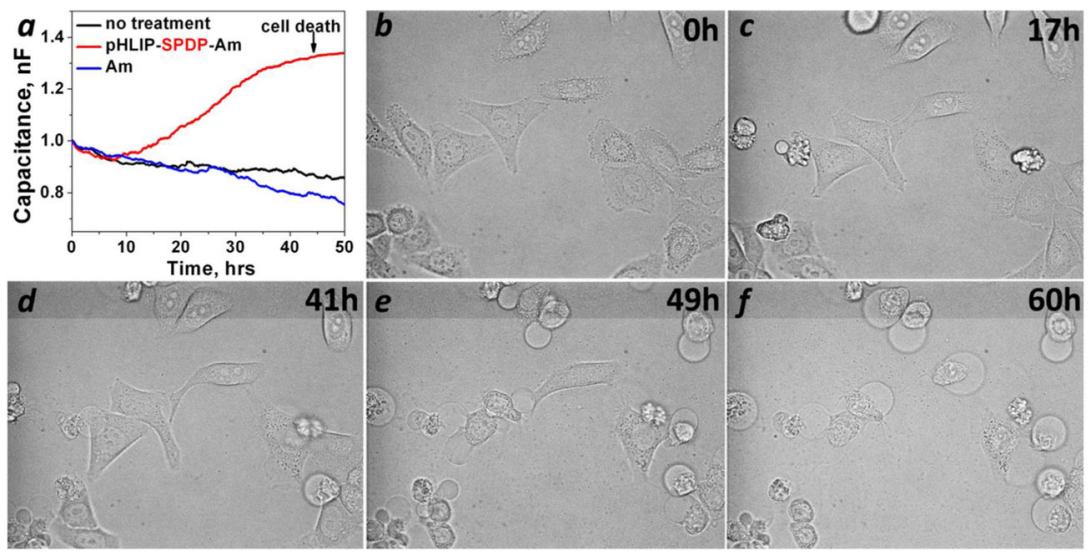

Figure 3. Time course of inhibition of cell proliferation

HeLa-GFP cells were treated with pHLIP-SPDP-Am for 2 hours in DMEM at pH 6.5 followed by the removal of the construct (zero time point) and the transfer of cells to the standard growth medium. The kinetics of inhibition of cell proliferation were monitored by changes of capacitance $(\boldsymbol{a})$ and cell morphology $(\boldsymbol{b}-\boldsymbol{f})$. 


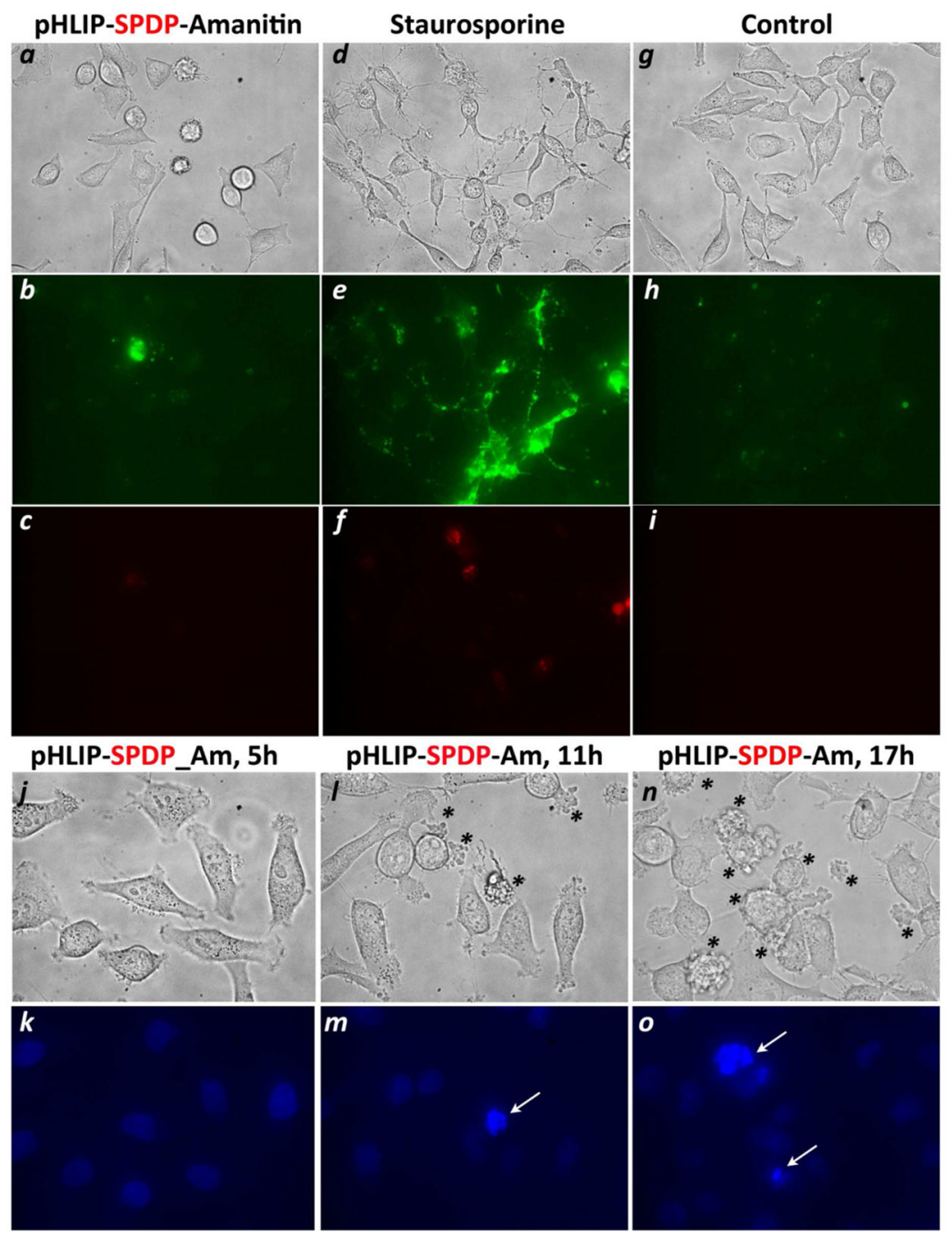

Figure 4. The pathway of cell death

Non-treated HeLa cells $(\boldsymbol{g}-\boldsymbol{i})$ and cells treated with pHLIP-SPDP-Am $(\boldsymbol{a}-\boldsymbol{c})$ at $11 \mathrm{~h}$ after treatment, and with staurosporine $(\boldsymbol{d}-\boldsymbol{f})$ at $4 \mathrm{~h}$ after treatment were stained with AnexinVFITC to monitor the appearance of phosphatidylserine at the outer surface of the plasma membrane $(\boldsymbol{b}, \boldsymbol{e}, \boldsymbol{h})$ and PI $(\boldsymbol{c}, \boldsymbol{f}, \boldsymbol{i})$. The changes in cell morphology $(\boldsymbol{j}, \boldsymbol{l}, \boldsymbol{n})$ and DNA fragmentation monitored by staining cell nuclear with DAPI $(\boldsymbol{k}, \boldsymbol{m}, \boldsymbol{o})$ of HeLa cells treated with pHLIP-SPDP-Am were observed at 5, 11 and 17 hours after the treatment. Only in a small population of cells, which show changes in cell morphology (shown by asterisk), the DNA fragmentation was observed (shown by arrows). 